\title{
Epidemiology of Chikungunya fever outbreak in Western Jamaica during July-December 2014
}

This article was published in the following Dove Press journal:

Research and Reports in Tropical Medicine

25 January 2017

Number of times this article has been viewed

\author{
Phuong N Pham' \\ LaQueena TWilliams' \\ Uduak Obot' \\ Luz A Padilla' \\ Maung Aung ${ }^{2}$ \\ Tomi F Akinyemiju' \\ April P Carson' \\ Pauline E Jolly' \\ 'Department of Epidemiology, \\ University of Alabama at Birmingham, \\ Birmingham, AL, USA; ${ }^{2}$ Epidemiology \\ Unit, Western Regional Health \\ Authority, Ministry of Health, \\ Montego Bay, Jamaica
}

Correspondence: Pauline E Jolly

Department of Epidemiology, School of

Public Health, University of Alabama at

Birmingham, Ryals Building, Room 217,

1665 University Boulevard, Birmingham,

AL 35294, USA

$\mathrm{Tel}+\mathrm{I} 205934$ I823

Fax + I 2059348665

Email jollyp@uab.edu
Objective: Our study describes the 2014 Chikungunya outbreak in Western Jamaica in terms of geographic distribution and trend of the outbreak over time, and evaluates clinical symptoms of the disease based on pre-existing conditions.

Methods: We conducted a retrospective, cross-sectional study of 609 clinically defined Chikungunya virus (CHIKV) fever cases that occurred in the four parishes of the Western Regional Health Authority of Jamaica from July 2014 to December 2014. Cases were not confirmed by laboratory tests but met clinical and epidemiological criteria of CHIKV fever.

Results: Our results show a propagated spread of CHIKV fever during the outbreak period with the peak at the end of October. Main urban cities, such as Montego Bay and Lucea, were identified as places that had high numbers of cases. Fever and arthralgia were the two most common clinical symptoms in CHIKV patients. Although a majority $(80 \%)$ of infants aged $<2$ years had up to four symptoms $(80 \%)$, the percentage of infants with higher numbers of symptoms (9-10) was higher than in older age groups. However, back pain was found to occur significantly more in older patients. Those with arthritis as a pre-existing condition were more likely to experience headache, asthenia, back pain, and periarticular edema.

Conclusion: These findings can help public health officials develop more effective programs to prevent the spread of CHIKV outbreaks by focusing on crowded urban cities. The findings indicate that those who are likely to develop a higher number of symptoms, such as young infants and people with pre-existing conditions, such as arthritis, should be more closely monitored to better manage the disease outcome.

Keywords: Chikungunya, Aedes mosquitoes, symptoms, outbreak, Jamaica, preexisting conditions

\section{Introduction}

Chikungunya virus (CHIKV) is a mosquito-borne virus that causes a febrile illness. The disease usually appears with high temperature, rash, debilitating arthralgia, and other flu-like symptoms, such as headache and fatigue. ${ }^{1}$ However, $\sim 3 \%-28 \%$ of people infected with CHIKV will be asymptomatic. The incubation period for those who develop symptomatic illness is typically 3-7 days (range, 1-12 days). ${ }^{2}$ People who were not previously infected with CHIKV (naïve individuals) are at risk of contracting the infection and developing clinical disease. ${ }^{2}$ The attack rates in communities in prior epidemics before the new epidemic in the Caribbean ranged from $38 \%$ to $63 \%$. ${ }^{2}$ Although most cases of CHIKV are not life threatening (case fatality rate from $0.1 \%$ to $5 \%$ ), the chronic arthritis that results from the infection poses a significant economic and public health burden. ${ }^{3}$ 
CHIKV was first discovered in 1952 in Tanzania. ${ }^{1}$ The virus is transmitted from human to human by Aedes mosquitoes with the two most common species being Aedes aegypti and Aedes albopictus. These two species can also transmit other mosquito-borne viruses, such as dengue and Zika. ${ }^{1,4}$ Humans are the main CHIKV reservoirs during epidemics. During inter-epidemic periods, other vertebrates such as nonhuman primates, rodents, birds, and some small mammals have been considered as potential reservoirs. ${ }^{2,5}$

There are three CHIKV genotypes: West African, EastCentral-South African or Indian Ocean lineage (IOL), and Asian., ${ }^{6,7}$ These genotypes represent the evolution and geographic distribution of the virus over the years. There is a relationship between the virus genotypes and the vectors. While the Asian lineage is mostly transmitted via $A$. aegypti, the IOL can efficiently use both $A$. aegypti and $A$. albopictus due to an adaptive mutation. ${ }^{6,8}$ A. albopictus can survive in cold weather and is generally more adapted to rural habitats than A. aegypti; therefore, CHIKV strains which adapted to A. albopictus can cause outbreaks in temperate regions such as Italy. ${ }^{9}$

According to the Centers for Disease Control and Prevention (CDC), before 2013, CHIKV outbreaks had been identified in many countries in Africa, Asia, Europe, and the Indian and Pacific Oceans. The disease used to occur at a low level in Africa for many years but in 1999-2000, a large outbreak occurred in the Democratic Republic of the Congo, and in 2007, an outbreak occurred in Gabon. ${ }^{1}$ CHIKV subsequently spread to India, starting with a major outbreak in islands of the Indian Ocean with a significant number of imported cases in Europe. ${ }^{1}$ In 2006-2007, a large outbreak of CHIKV occurred in India. ${ }^{1}$ Some other countries in SouthEast Asia such as Malaysia, Singapore, and Thailand were also affected. ${ }^{1}$ Since 2005 , there have been $>1.9$ million cases of CHIKV reported in India, Indonesia, Maldives, Myanmar, and Thailand. ${ }^{1}$

In late 2013, the first local transmission of CHIKV in the Americas was identified in Caribbean countries and territories. ${ }^{1}$ In December 2013, two laboratory-confirmed autochthonous cases were reported in the Caribbean island of St. Martin. ${ }^{1}$ Since then, local transmission has occurred in over 43 countries of the Americas and has become the first outbreak of Chikungunya with autochthonous transmission in the Americas. ${ }^{1}$ As of April 2015, over 1,379,788 suspected cases of Chikungunya have been recorded in the Caribbean islands, Latin American countries, and the United States of America with 191 deaths. $^{1}$

One of many concerns regarding this new epidemic in the Caribbean and Latin America is that CHIKV has been rapidly spreading through autochthonous transmission due to a high prevalence of $A$. aegypti mosquitoes in the area.,10 Another problem is that most of the Caribbean and Latin American people presumably have no immunity to the virus, and diagnosis capabilities in the region are quite limited. ${ }^{6}$ Currently, there is no specific treatment or commercial vaccine for CHIKV; therefore, it is important for public health officials to conduct surveillance of the epidemic as well as to develop plans to control current and future outbreaks. ${ }^{4,11}$

In this study, we describe the CHIKV epidemic in the western region of Jamaica, one of the countries in the Caribbean that was declared a state of emergency for CHIKV in $2014 .{ }^{12}$ We describe the outbreak in terms of geographic distribution and disease trend over time as well as assess the clinical symptoms and number of symptoms across age groups. We also evaluated the severity of Chikungunya disease in terms of the presence of specific CHIKV symptoms in patients with pre-existing conditions (cardiovascular disease [CVD], arthritis, and diabetes) compared with those without pre-existing conditions.

\section{Methods \\ Data collection}

This is a retrospective cross-sectional study of clinically suspected Chikungunya fever cases without serological confirmation from the Western Regional Health Authority (WRHA) of Jamaica during July 2014 to December 2014. The WRHA, one of Jamaica's four regional health authorities, serves $>472,000$ people at 84 health care centers and 4 hospitals in the four parishes of Western Jamaica, namely, Hanover, St. James, Trelawny, and Westmoreland. Ethical approval for the study was provided by the Institutional Review Board (IRB) of the University of Alabama at Birmingham and the WRHA. A waiver of patient consent was requested and granted by the review boards. The human resource and expense that would have been required for patient consent was prohibitive and would have prevented the Ministry of Health from obtaining crucial data in understanding the outbreak, and in planning for ongoing CHIKV transmission and future outbreaks in the country. Strict precautions were taken to maintain confidentiality, and identification numbers instead of patient names were placed on the survey instruments.

CHIKV is a Class I notifiable disease and must be reported to the Ministry of Health by public and private health facilities in Jamaica. Once a clinician sees a person with suspected CHIKV fever, notification of the patient information is sent to the local health department using a specific form. The local health department then assigns a Public Health 
Nurse and Public Health Inspector to investigate the case. The completed investigation forms are then submitted to the Ministry of Health for final classification.

For this study, patient records were obtained from the Epidemiology Unit at the WRHA and reviewed to collect limited sociodemographic information (age, sex, and address) and clinical data, including pre-existing clinical conditions.

\section{Inclusion criteria}

Individuals residing in any of the 4 parishes served by the WRHA who were seen at a public or private health facility (with or without being hospitalized) between July 2014 and December 2014, and who met the standard clinical case definition of CHIKV fever were included in the study.

The Jamaican Ministry of Health (MoH) used the World Health Organization, South-East Asia Region case definition of Chikungunya fever (patient with acute onset of fever $>38.5^{\circ} \mathrm{C}$ and severe arthralgia or arthritis not explained by other medical conditions) as their clinical case definition. ${ }^{13}$ The MoH first confirmed that there was a CHIKV outbreak on the island, thereby meeting the epidemiological criteria. Once the outbreak was confirmed, the $\mathrm{MoH}$ concentrated on using the limited resources available to ramp-up hospital and clinical services to care for patients and to put measures in place to control infection transmission. Therefore, further laboratory testing post-outbreak confirmation was not done. However, the strict clinical definition of CHIKV cases was adhered to by clinical personnel.

\section{Description of variables}

Exposures of interest are pre-existing conditions and demographic factors, including age and sex. Pre-existing conditions such as CVD, diabetes, and arthritis were categorized as "yes" for having the condition and "no" for not having it. This clinical information was extracted from medical records. Age was categorized into five groups: $<2,2-<15,15-<45$, $45-<65$, and $\geq 65$ years according to the provisional guideline on standard international age classification for general purpose, under the World Health Organization section. ${ }^{14}$ However, the first group was adjusted from $<1$ to $<2$ years of age to increase the sample size of this group. Sex was dichotomized as male or female.

The outcomes of interest are symptoms (fever, arthralgia, headache, skin manifestation, asthenia, myalgia, back pain, nausea, vomiting, and periarticular edema [swollen joints]) and number of symptoms. This clinical information was extracted from medical records. Each symptom was categorized as "yes" for having the symptom and "no" for not having it. Number of symptoms was calculated and divided into five groups: $1-2$ symptoms, 3-4 symptoms, 5-6 symptoms, 7-8 symptoms, and 9-10 symptoms.

Other demographic information such as parish (Hanover, St. James, Trelawny, and Westmoreland), type of health facility (hospital, clinic, and private practitioner), and hospitalization were treated as categorical variables. This information was obtained from the CHIKV investigation form.

\section{Data analysis}

Cases of CHIKV by date of review were used to plot an epidemic curve that shows the distribution of the disease over time. As the date of onset of illness was not recorded, the dates when cases were reviewed by health professionals at medical facilities (date of review) were considered as date of disease onset. Since most persons in Jamaica who experience a condition exhibiting signs and symptoms seek health care within 2-3 days of onset, the date of reporting would be $\sim 2-3$ days post-onset and should not affect our results much.

Address of each patient was placed on a map using the open-source geographic information system QGIS and the web mapping MangoMap. A graph for number of cases in each parish was also made using Microsoft Excel.

Descriptive analysis was performed for sociodemographic factors (age, sex, parish, type of health facility) and clinical symptoms by calculating number and percentage of cases. Symptoms and number of symptoms were examined across age groups and are also presented as number and percentage of cases. $p$ values were obtained by using chi-square or Fisher's exact test (in case $25 \%$ of the cells were $<5)$. Statistical analyses were performed using SAS 9.4 software.

The likelihood of having a specific symptom (fever, arthralgia, headache, skin manifestation, asthenia, myalgia, back pain, nausea, vomiting, and periarticular edema) among those with a particular pre-existing condition (CVD, diabetes, and arthritis) compared with those without the pre-existing condition was determined by calculating the odds ratio and $95 \%$ confidence interval. The dependent variable is symptoms and the independent variable is pre-existing condition. There are three models for each symptom corresponding to three pre-existing conditions. Adjusted odds ratios were calculated by adjusting for age, sex, and other pre-existing conditions (those having CVD were adjusted for diabetes and arthritis, those having diabetes were adjusted for CVD and arthritis, and those having arthritis were adjusted for CVD and diabetes). 


\section{Results}

\section{Outbreak description}

During the studied period, from July 2014 to December 2014, a total of 609 clinical suspected CHIKV cases were identified in the four parishes of Western Jamaica: Hanover, St. James, Westmoreland, and Trelawny. The first case was reported on July 13, 2014, at the Trelawny Health Department. Nearly 1 month later, two new cases were identified in St. James on August 11 and August 12. After that, the number of cases gradually increased and peaked on October 30, 2014, with 39 cases. The epidemic then slowly declined until the end of December (Figure 1).
Among the four parishes, St. James and Hanover had the highest number of cases with 264 cases and 220 cases, respectively. These numbers account for $\sim 80 \%$ of all cases of CHIKV in the area. As shown in Figure 2, cases were mostly found around the Montego Bay area, the capital city of St. James. Lucea, the capital city of Hanover, and Savanna-la-mar, the capital city of Westmoreland, also had many cases. However, only $\sim 70 \%$ of all the addresses of CHIKV cases could be identified and mapped (red dots in Figure 2), the remaining addresses could not be found by QGIS. Figure 3 shows the percent breakdown of CHIKV cases by parish.

Cases of Chikungunya by date of onset, Jamaica, 2014

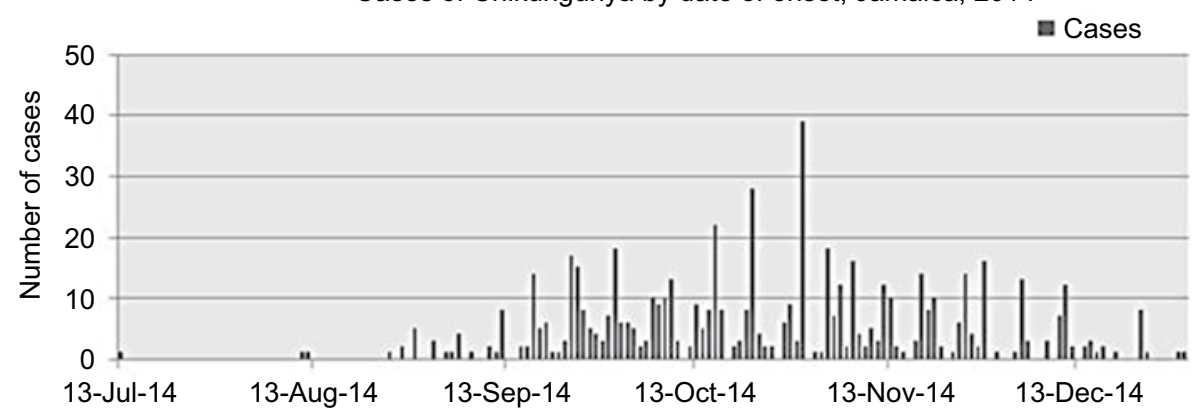

Figure I Epidemic curve of CHIKV outbreak in Western Jamaica from July 2014 to December 2014.

Note: CHIKV cases represent clinically suspected cases and were not confirmed by serological or other diagnostic methods.

Abbreviation: $\mathrm{CHIKV}$, Chikungunya virus.

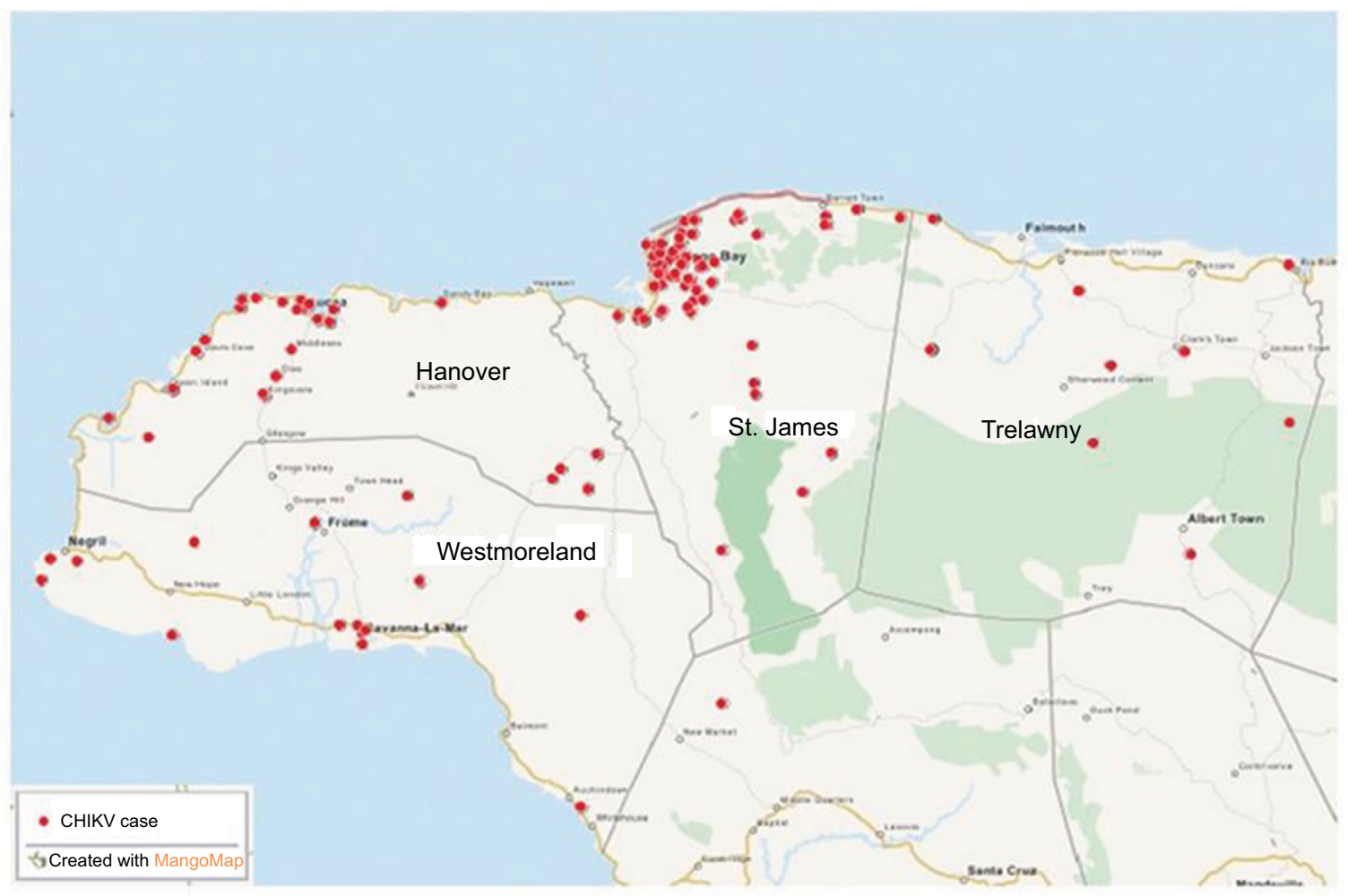

Figure 2 Geographic distribution of CHIKV outbreak in Western Jamaica from July to December 2014.

Abbreviation: CHIKV, Chikungunya virus. 


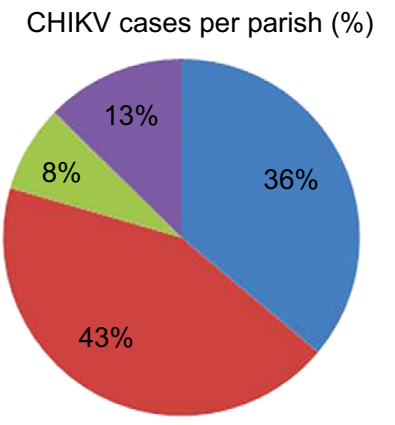

Figure 3 Percentage of CHIKV cases in four parishes. Abbreviation: $\mathrm{CHIKV}$, Chikungunya virus.

\section{Sociodemographic and clinical characteristics of cases}

CHIKV affected people in different age groups and both sexes. Table 1 shows that $62.2 \%$ of CHIKV cases were female and $37.8 \%$ were male. There were 18 cases $(3 \%)<2$ years of age and 28 cases $(4.6 \%)>65$ years of age. The majority of cases (47.7\%) were aged 15-45. Most CHIKV patients visited a clinic (86.1\%); $11.6 \%$ went to a hospital and $2.3 \%$ to a private practitioner.

The most common symptoms of CHIKV cases were fever and arthralgia. Table 1 demonstrates that $100 \%$ of patients had fever and $94.2 \%$ had arthralgia. The available data showed that arthralgia involved joint pain in the hand, wrist, foot, ankle, elbow, knee, and hip, and occurred on both left and right sides. The other symptoms appeared in $~ 50 \%$ or less of the cases. These include headache (52.1\%), skin manifestation (40.3\%), asthenia (40.0\%), myalgia (33.5\%), back pain (31.4\%), and nausea (16.9\%). Periarticular edema occurred in only $1.2 \%$ of cases. We also noticed that there were some differences in the frequency of several symptoms between male and female such as skin manifestation and periarticular edema with higher number of cases among females compared with males ( $46.7 \%$ vs. $29.7 \%$ and $14.6 \%$ vs. $5.5 \%$, respectively).

Regarding pre-existing conditions of CHIKV cases, 43 cases $(8.3 \%)$ had CVD, 33 cases $(6.2 \%)$ had diabetes, and 185 cases (34.3\%) had arthritis. Some of these cases had multiple pre-existing conditions: 10 cases had both CVD and diabetes, 9 cases had both diabetes and arthritis, 11 cases had CVD and arthritis, and 5 cases had all three conditions. Twenty-one female patients $(5.5 \%)$ were pregnant. Compared with males, females had a higher number of cases with pre-existing conditions, especially CVD (10\% vs $4.8 \%)$ and diabetes ( $7.7 \%$ vs. $3.3 \%)$.

Frequency and percentage of CHIKV symptoms across age groups are presented in Table 2. Back pain occurred
Table I Statistical summary of sociodemographic and clinical factors of CHIKV cases according to pre-existing conditions

\begin{tabular}{|c|c|c|c|}
\hline $\begin{array}{l}\text { Sociodemographic } \\
\text { and clinical factors }\end{array}$ & $\begin{array}{l}\text { Male } \\
(n=230), \\
N(\%)\end{array}$ & $\begin{array}{l}\text { Female } \\
(n=379), \\
N(\%)\end{array}$ & $\begin{array}{l}\text { Total } \\
(n=609), \\
N(\%)\end{array}$ \\
\hline \multicolumn{4}{|l|}{ Age, years } \\
\hline$<2$ & $9(3.93)$ & $9(2.39)$ & $18(3.0)$ \\
\hline $2-<15$ & $82(35.81)$ & $68(18.04)$ & $150(24.7)$ \\
\hline $15-<45$ & $98(42.79)$ & $191(50.66)$ & $289(47.7)$ \\
\hline $45-<65$ & $30(13.10)$ & $91(24.14)$ & $|2|(20.0)$ \\
\hline$\geq 65$ & $10(4.37)$ & $18(4.77)$ & $28(4.6)$ \\
\hline \multicolumn{4}{|l|}{ Parish } \\
\hline Hanover & 85 (36.96) & $135(35.62)$ & $220(36.1)$ \\
\hline St. James & $99(43.04)$ & $165(43.54)$ & $264(43.4)$ \\
\hline Trelawny & 17 (7.39) & $31(8.18)$ & $48(7.9)$ \\
\hline Westmoreland & $29(|2.6|)$ & $48(12.66)$ & $77(12.6)$ \\
\hline \multicolumn{4}{|l|}{ Type of health care } \\
\hline Hospital & $22(9.78)$ & $48(12.73)$ & $70(11.6)$ \\
\hline Clinic & $199(88.44)$ & $319(84.62)$ & $518(86.1)$ \\
\hline Private practitioner & $4(1.78)$ & $10(2.65)$ & $14(2.3)$ \\
\hline Hospitalization & $16(7.11)$ & $20(5.33)$ & $36(6.00)$ \\
\hline \multicolumn{4}{|l|}{ Symptoms } \\
\hline Fever & $230(100.00)$ & $379(100.00)$ & $609(100)$ \\
\hline Arthralgia & $209(93.3)$ & $354(94.65)$ & $563(94.2)$ \\
\hline Headache & $117(53.67)$ & $188(51.09)$ & $305(52.1)$ \\
\hline Skin manifestation & $66(29.73)$ & $17 \mid(46.72)$ & $237(40.3)$ \\
\hline Asthenia & $93(43.66)$ & $136(37.88)$ & $229(40.0)$ \\
\hline Myalgia & $67(32.21)$ & $123(34.26)$ & $190(33.5)$ \\
\hline Back pain & $66(31.58)$ & $113(31.30)$ & $179(31.4)$ \\
\hline Nausea & $36(16.67)$ & $62(17.08)$ & $98(16.9)$ \\
\hline Vomiting & $32(14.55)$ & $48(13.26)$ & $80(13.7)$ \\
\hline Periarticular edema & II (5.53) & $48(14.63)$ & $59(1.2)$ \\
\hline \multicolumn{4}{|c|}{ Pre-existing conditions } \\
\hline Arthritis & $60(29.85)$ & $125(36.13)$ & $185(34.3)$ \\
\hline Cardiovascular disease & $9(4.86)$ & $34(10.00)$ & $43(8.3)$ \\
\hline Diabetes & $6(3.28)$ & $27(7.76)$ & $33(6.2)$ \\
\hline Pregnancy & - & $21(5.54)$ & $21(5.54)$ \\
\hline
\end{tabular}

Abbreviation: $\mathrm{CHIKV}$, Chikungunya virus.

more in the older groups ( $\geq 15$ years old) with $\sim 40 \%$ compared with the younger age groups $(<2$ and $2-<15)$ with $\sim 10 \%$. Table 2 also shows higher numbers and percentages of CHIKV symptoms such as headache $(60.36 \%)$ and skin manifestation (51.08\%) among patients aged $15-<45$ years compared with other age groups.

Number of cases was also calculated and presented across age group, sex, parish, type of health care, and hospitalization status (Table 3). In general, most cases had 3-4 symptoms $(42.36 \%)$. There were $18.72 \%$ of cases having up to 2 symptoms, $27.26 \%$ of cases had 5-6 symptoms, 9.36\% had 7-8 symptoms, and $2.3 \%$ had $9-10$ symptoms. The infant group had the highest percentage of cases with only 1-2 symptoms (44.4\%), and over $80 \%$ of cases in the infant group had 1-4 symptoms. The majority of cases in the other groups had 3 to 6 symptoms. Those who were hospitalized 
Table 2 Frequency and percentage of CHIKV symptoms across age groups

\begin{tabular}{|c|c|c|c|c|c|c|}
\hline \multirow[t]{2}{*}{ Symptom } & \multicolumn{6}{|l|}{ Age group } \\
\hline & $\begin{array}{l}<2 \\
(n=18), N(\%)\end{array}$ & $\begin{array}{l}2-<15 \\
(n=150), N(\%)\end{array}$ & $\begin{array}{l}\text { I5-<45 } \\
(n=289), N(\%)\end{array}$ & $\begin{array}{l}45-<65 \\
(n=|2|), N(\%)\end{array}$ & $\begin{array}{l}\geq 65 \\
(n=28), N(\%)\end{array}$ & $p$-Value* \\
\hline Fever & $18(100.0)$ & $150(100.0)$ & $289(100.0)$ & $12 \mid(100.0)$ & $28(100.0)$ & - \\
\hline Arthralgia & $16(88.89)$ & $140(93.96)$ & $269(94.39)$ & $109(93.97)$ & $26(96.30)$ & 0.88 \\
\hline Headache & $3(17.65)$ & $71(48.30)$ & $166(60.36)$ & $50(43.10)$ & $14(50.00)$ & 0.0004 \\
\hline Skin manifestation & 7 (38.89) & $42(28.38)$ & $142(51.08)$ & $40(34.78)$ & $4(|4.8|)$ & $<0.0001$ \\
\hline Asthenia & $4(23.53)$ & $52(36.11)$ & 118 (44.19) & $40(35.09)$ & $12(44.44)$ & 0.19 \\
\hline Myalgia & $5(29.4 I)$ & $38(26.95)$ & $92(34.59)$ & $43(37.72)$ & $9(34.62)$ & 0.42 \\
\hline Back pain & $2(11.76)$ & $15(10.56)$ & $106(39.55)$ & $44(38.94)$ & II (40.74) & $<0.0001$ \\
\hline Nausea & I (5.88) & $24(16.44)$ & $54(20.07)$ & $12(10.26)$ & $6(22.22)$ & 0.10 \\
\hline Vomiting & $3(16.67)$ & $30(20.4 I)$ & $34(12.55)$ & $7(6.09)$ & $5(17.86)$ & 0.02 \\
\hline Periarticular edema & I (5.56) & $6(4.5 \mathrm{I})$ & $33(|3.3|)$ & $16(15.69)$ & $2(8.70)$ & 0.04 \\
\hline
\end{tabular}

Notes: *p-values were calculated using chi-square or Fisher's exact test. Bold $p$-values are statistically significant $(<0.05)$.

Abbreviation: CHIKV, Chikungunya virus.

Table 3 Number of symptom across age group, parishes, and type of health care system

\begin{tabular}{|c|c|c|c|c|c|c|}
\hline \multirow{2}{*}{$\begin{array}{l}\text { Sociodemographic } \\
\text { factors }\end{array}$} & \multicolumn{5}{|c|}{ Number of symptoms } & \multirow[t]{2}{*}{$p$-Value* } \\
\hline & I-2, N (\%) & $3-4, N(\%)$ & $5-6, N(\%)$ & 7-8, N (\%) & 9-10, N (\%) & \\
\hline \multicolumn{7}{|l|}{ Age, years } \\
\hline$<2(n=18)$ & $8(44.44)$ & 7 (38.98) & I (5.56) & I (5.56) & I (5.56) & \multirow[t]{5}{*}{0.0007} \\
\hline $2-<15(n=150)$ & $44(29.33)$ & $60(40.00)$ & $35(23.33)$ & $8(5.33)$ & $3(2.00)$ & \\
\hline $15-<45(n=289)$ & $32(11.07)$ & $125(43.25)$ & $89(30.80)$ & $35(12.11)$ & $8(2.77)$ & \\
\hline $45-<65(n=121)$ & $26(21.49)$ & $54(44.63)$ & $29(23.97)$ & II (9.09) & I $(0.83)$ & \\
\hline$\geq 65(n=28)$ & $4(14.29)$ & $12(42.86)$ & $10(35.71)$ & $2(7.14)$ & $0(0.00)$ & \\
\hline \multicolumn{7}{|l|}{ Sex } \\
\hline Male $(n=230)$ & $46(20.00)$ & $103(44.78)$ & $63(27.39)$ & $13(5.65)$ & $5(2.17)$ & \multirow[t]{2}{*}{0.18} \\
\hline Female $(n=379)$ & $68(17.94)$ & I55 (40.90) & $103(27.18)$ & $44(11.6 I)$ & $9(2.37)$ & \\
\hline \multicolumn{7}{|l|}{ Parish } \\
\hline Hanover $(n=220)$ & $44(20.00)$ & $91(41.36)$ & $65(29.55)$ & $17(7.73)$ & $3(1.36)$ & \multirow[t]{4}{*}{0.29} \\
\hline St. James $(n=264)$ & $52(19.7)$ & $120(45.45)$ & $57(21.59)$ & $28(10.61)$ & $72.65)$ & \\
\hline Trelawny $(n=48)$ & $9(18.75)$ & $19(39.58)$ & $14(29.17)$ & $5(10.42)$ & I (2.08) & \\
\hline Westmoreland (77) & $9(11.69)$ & $28(36.36)$ & $30(38.96)$ & 7 (9.09) & $3(3.90)$ & \\
\hline \multicolumn{7}{|l|}{ Type of health care } \\
\hline Hospital $=I(n=70)$ & $16(22.86)$ & $29(41.43)$ & $22(31.43)$ & $2(2.86)$ & I (I.43) & \multirow[t]{3}{*}{0.07} \\
\hline Clinic $=2(n=5 \mid 8)$ & $97(18.73)$ & $222(42.86)$ & $135(26.06)$ & $51(9.85)$ & $13(2.5 \mathrm{I})$ & \\
\hline Private practitioner $(n=14)$ & I (7.14) & $3(21.43)$ & $6(42.86)$ & $4(28.57)$ & $0(0.00)$ & \\
\hline \multicolumn{7}{|l|}{ Hospitalization } \\
\hline Yes $(n=36)$ & $3(8.33)$ & $12(33.33)$ & $16(44.44)$ & $3(8.33)$ & $2(5.56)$ & \multirow[t]{3}{*}{0.06} \\
\hline No $(n=564)$ & $108(19.15)$ & $243(43.09)$ & $147(26.06)$ & $54(9.57)$ & $12(2.13)$ & \\
\hline Total & $114(18.72)$ & $258(42.36)$ & $166(27.26)$ & $57(9.36)$ & $14(2.30)$ & \\
\hline
\end{tabular}

Notes: *p-values were calculated using chi-square or Fisher's exact test. The bold $p$-value is statistically significant $(<0.05)$.

were two fold higher in percentage of having 9-10 symptoms compared with non-hospitalized patients. No significant differences in number of symptoms were identified among parishes and type of healthcare facility.

\section{Association between pre-existing conditions and clinical symptoms}

Table 4 shows the likelihood of having CHIKV symptoms according to pre-existing conditions before and after adjusting for age, sex, and other pre-existing conditions. For those with
CVD and diabetes, the likelihood of having a specific symptom did not differ much compared with those without CVD and diabetes, except for back pain (OR=2.5 and 2.3, respectively) and periarticular edema ( $\mathrm{OR}=2.5$ and 2.7, respectively). There were significant associations of age with back pain and periarticular edema (Table 2). Back pain occurred more frequently in the older age group ( $>15$ years) compared with the younger group ( $\leq 15$ years) nearly four times (Table 2 ). In fact, according to Table 4 , back pain occurred more frequently in the older group ( $>15$ years) compared with the younger 
Table 4 The likelihood of having CHIKV symptoms according to pre-existing conditions

\begin{tabular}{|c|c|c|c|c|c|c|}
\hline \multirow{3}{*}{$\begin{array}{l}\text { Clinical } \\
\text { symptoms }\end{array}$} & \multicolumn{6}{|c|}{ Pre-existing conditions } \\
\hline & \multicolumn{2}{|l|}{ CVD $(n=43)$} & \multicolumn{2}{|l|}{$\operatorname{DM}(n=33)$} & \multicolumn{2}{|l|}{ ARTH $(n=185)$} \\
\hline & OR (95\% Cl) & AOR (95\% Cl) & OR (95\% CI) & AOR $(95 \% \mathrm{Cl})$ & OR (95\% Cl) & AOR $(95 \% \mathrm{Cl})$ \\
\hline Fever & - & - & - & - & - & - \\
\hline Arthralgia & $0.9(0.25-2.98)$ & $0.6(0.13-2.48)$ & - & - & $0.02(0.01-0.10)$ & $0.03(0.01-0.12)$ \\
\hline Headache & $0.8(0.44-1.56)$ & $0.9(0.40-1.90)$ & I.I (0.53-2.17) & $1.03(0.42-2.55)$ & $1.5(1.07-2.21)$ & $1.7(1.15-2.50)$ \\
\hline Skin manifestation & $0.6(0.28-1.12)$ & $0.8(0.36-1.84)$ & $0.6(0.25-1.21)$ & $0.8(0.29-2.04)$ & $\mathrm{I} .3(0.87-1.8 \mathrm{I})$ & $1.2(0.80-1.78)$ \\
\hline Asthenia & $1.2(0.64-2.33)$ & $1.2(0.53-2.61)$ & I.I (0.53-2.3I) & $0.8(0.32-2.13)$ & $1.5(1.0 I-2.11)$ & $1.6(1.06-2.30)$ \\
\hline Myalgia & $\mathrm{I} .7(0.89-3.4 \mathrm{I})$ & $1.8(0.80-3.95)$ & $1.5(0.7 I-3.10)$ & $0.8(0.32-2.17)$ & $1.4(0.98-2.11)$ & $1.3(0.89-1.99)$ \\
\hline Back pain & $2.5(1.31-4.76)$ & $2.1(0.92-4.68)$ & $2.3(1.08-4.88)$ & $1.2(0.46-3.32)$ & $2.6(1.80-3.89)$ & $3.1(1.98-4.72)$ \\
\hline Nausea & $0.9(0.36-2.17)$ & $1.1(0.37-3.03)$ & $1.2(0.49-3.12)$ & $1.5(0.47-5.06)$ & $1.9(1.17-2.92)$ & $2.2(1.36-3.66)$ \\
\hline Vomiting & $1.2(0.47-2.89)$ & $1.9(0.6 I-5.91)$ & $1.6(0.65-4.19)$ & $2.6(0.7 I-9.49)$ & I.I (0.67-I.87) & $1.3(0.77-2.35)$ \\
\hline Periarticular edema & $2.5(1.11-5.59)$ & $2.3(0.90-6.02)$ & $2.7(1.09-6.65)$ & $2.0(0.63-6.38)$ & $3.3(1.85-5.78)$ & $2.6(1.40-4.75)$ \\
\hline
\end{tabular}

Notes: AOR: odds ratio adjusted for age, sex, and other pre-existing conditions; OR, odds of having a specific symptom among those with CVD or DM or ARTH/odds of having a specific symptom among those without CVD or DM or ARTH; OR and AOR were calculated using logistic regression models. Bold values indicate statistical significance.

Abbreviations: AOR, adjusted odds ratio; ARTH, arthritis; $\mathrm{Cl}$, confidence interval; CHIKV, Chikungunya virus; CVD, cardiovascular disease; DM, diabetes mellitus; OR, odds ratio.

group ( $\leq 15$ years) with nearly four times. Also, percentage of periarticular edema was found to be higher in patients aged from 15 to 65 years (Table 2) and female patients (Table 1).

In contrast to CVD and diabetes, those with arthritis as a pre-existing condition, were more likely to have many CHIKV symptoms after adjusting for age, sex, CVD, and diabetes. These symptoms include headache $(\mathrm{AOR}=1.7,95 \% \mathrm{CI}=1.15-2.50)$, asthenia $(\mathrm{AOR}=1.6,95 \% \mathrm{CI}=1.06-2.3)$, back pain $(\mathrm{AOR}=3.1$, 95\% $\mathrm{CI}=1.98-4.72$ ), nausea $(\mathrm{AOR}=2.2,95 \% \mathrm{CI}=1.36-3.66)$, and periarticular edema $(\mathrm{AOR}=2.6,95 \% \mathrm{CI}=1.40-4.75)$. The only CHIKV symptom that was less likely to occur in those with arthritis compared with those without was arthralgia ( $\mathrm{AOR}=0.03,95 \% \mathrm{CI}=0.01-0.12$ ), although the frequency of this symptoms in both groups is high with $>80 \%$ cases.

\section{Discussion}

The first CHIKV case in the WRHA was identified on July 13, 2014, in the Trelawny Health Department, but it seems that the autochthonous transmission had not started until the second and third cases were found on August 11 and 12 in St. James. The epidemic curve with successively taller peaks initially separated by one incubation period clearly demonstrated a propagated spread of the disease with newly infected people serving as a source for vector transmission to others. ${ }^{15}$ Around the end of October, the Jamaica government declared a national emergency for CHIKV outbreak in an effort to control the disease. It was considered as a step toward ensuring that people would take this particular situation seriously and would work together to combat the outbreak. As a result, the epidemic decreased gradually and ended in December.

The principal vector responsible for the transmission of CHIKV in the Caribbean is the A. aegypti which is found mostly in urban areas. ${ }^{16}$ That may explain why a majority of CHIKV cases reported in our study were around Montego Bay area, the capital city of St. James, which has the largest population in Western Jamaica. According to the census in 2011, the population of Montego Bay ranked fourth in the country with 110,115 people, after Kingston, Spanish Town, and Portmore. In fact, population growth has led to issues such as massive unplanned, uncontrolled urbanization in many cities and deteriorating housing, water and sewage waste management systems. These in turn create ideal conditions for the transmission of mosquito borne diseases. ${ }^{17}$ The difference in the distribution of the disease among parishes may also come from the effectiveness of public health control programs and other factors such as agricultural practices in the parishes.

CHIKV infected both males and females and across age groups. The much higher percentage of cases observed for females $(62 \%)$ than for males $(38 \%)$ in our study does not reflect the female to male ratio in the Jamaican population or in the western region of Jamaica where the study was conducted. The most recent Jamaican census data reported a total of 472,611 people living in the western region, and this total was almost evenly divided between males and females (50.2\% males and $49.8 \%$ females). ${ }^{18}$ The higher percentage of cases among females may be due to higher levels of exposure to infected vectors in the home environment since females spend more time at home and the mosquitoes are commonly found indoors. ${ }^{19}$ According to the global information society watch, a majority of household workers in Jamaica are women. ${ }^{20}$ Also, the rate of unemployment among women was nearly double the rate of unemployment among men $(16.8 \%$ for women compared with $9.5 \%$ for men, 2011). ${ }^{20}$ The differences in rate of infection among the sexes may also be due 
to poor health-seeking behavior among males in Jamaica. ${ }^{21}$ A CHIKV outbreak study conducted in the USA Virgin Islands reported very similar finding to ours, in that, $60 \%$ of laboratory-positive CHIKV cases were females compared with $40 \%$ males. ${ }^{22}$ Since that study consisted of people who voluntarily sought care for their symptoms (similar to our study), the data may reflect differences in health-seeking behavior among females and males. On the other hand, higher CHIKV infection rates were reported in Kerala, India. This is believed to be due to high occupational risk among males engaged in plantation activities where they are exposed to bites from infected vectors. ${ }^{23}$

The difference in number of cases in the age groups that we found in the study may not indicate vulnerability of the group but may just reflect the population structure in Jamaica which has $\sim 50 \%$ in the $15-45$ age group. ${ }^{24}$

Clinical symptoms presented in our patients are consistent with those reported by the CDC. Arthralgia (joint pain) is the most common symptom in CHIKV with the frequency usually ranging from $71 \%$ to $100 \%$ and is usually symmetric (Pan American Health Organization [PAHO]); headache, skin manifestation (rash), asthenia (fatigue), back pain, myalgia (muscle pain), nausea, and vomiting are other common symptoms. Fever was present in $100 \%$ of cases as it was a defining symptom for CHIKV. Back pain was found to occur at higher frequency in older age groups and is one of the chronic problems lasting after recovering from the illness. Regarding number of symptoms, the highest percentage of cases with 9-10 symptoms was found in the infant group ( $<2$ years). This may indicate severe disease in this group, which is consistent with the CDC statement that newborn and elderly ( $\geq 65$ years) are at risk for more severe disease. However, there were only 18 cases aged $<2$ years in our study; thus, a larger sample size would be necessary for a more meaningful conclusion. The fact that no differences in number of symptoms among cases were found among parishes and type of health facilities may reflect the consistency in symptom diagnosis across different parishes in Western Jamaica.

Before adjusting for age, sex, and other pre-existing conditions, those with CVD or diabetes were more likely to have back pain and periarticular edema compared with those without CVD or diabetes, but after adjusting for age, sex, and pre-existing conditions, no statistical significance was detected. This means that these factors are not distributed evenly between the two groups and are confounding for the association. In fact, in our study, we did find an association between age and pre-existing condition (CVD, diabetes, $p$ value $<0.0001$ ), as well as between age and back pain
( $p$ value $<0.0001$ ), and between age and periarticular edema ( $p$ value $=0.04)$. For those with arthritis, on the other hand, even after adjusting for age, sex, and other pre-existing conditions, we still found significant associations with specific symptoms. Those with arthritis were more likely to have headache, asthenia, back pain, nausea, and periarticular edema but less likely to have arthralgia than those without arthritis. The reason may be that these people who already had arthritis may have been taking medication rendering the arthralgia non-evident. Further studies should focus on disease outcomes with Chikungunya. For example, trying to identify factors associated with severe outcomes such as longlasting arthralgia may identify a way to control this outcome.

Although the number of symptoms and the appearance of a specific symptom may not accurately indicate the severity of the disease, the differences we found among age groups and between those with and without pre-existing conditions would suggest that there should be special precautions for people in these specific groups, such as those with arthritis, infants, and older people. For example, using insect repellent, wearing long sleeve shirts and pants, and sleeping under a mosquito bed-net to protect them from mosquito bites should be recommended. Also, once identified with the disease, these patients may need to receive close care from doctors.

Since effective control of mosquito vectors is difficult, the most effective means of controlling the spread of CHIKV and other similar vector-borne viruses would be by vaccination. Although there are no licensed CHIKV vaccines, several vaccine candidates that have been shown to be immunogenic and generally well tolerated are currently in pre-clinical and clinical development. ${ }^{3}$ A live-attenuated CHIKV vaccine candidate developed by the U.S. Army Medical Research Institute of Infectious Diseases (USAMRIID) and tested in phase 2 trial was not developed further due to fear of reversion to the harmful virus. ${ }^{25} \mathrm{~A}$ CHIKV virus-like particle (VLP) vaccine developed by the National Institute of Allergy and Infectious Diseases (NIAID), USA, is currently in phase 2 clinical trial, and a measles vector CHIKV vaccine developed by Themis Bioscience GmbH/Institut Pasteur is slated for phase 2 trials in $2016 .{ }^{26,27}$ In low- and middle-income countries (LMIC) such as Jamaica where CHIKV has now become endemic, a licensed CHIKV vaccine would be useful during an outbreak, in vaccination campaigns, or as part of the standard immunization schedule. A single-dose vaccine would be more appropriate for use in an outbreak or in vaccination campaigns. Our study findings of higher number of symptoms in infants and of significantly more pain in older adults indicate that an effective and safe CHIKV vaccine 
would be most useful in the pediatric and adult populations in Jamaica, especially in adults with arthritis and other preexisting health conditions.

\section{Limitations}

This study has certain limitations which should be considered in interpreting the data. First, the study sample consists only of cases who sought health care for their symptoms and may over represent CHIKV cases who had more severe disease or those who sought health care more quickly. Second, the analysis was conducted on clinically diagnosed CHIKV cases which were not confirmed due to lack of resources for CHIKV confirmatory tests. Data on disease outcome were not available, so disease severity or other health outcome such as mortality could not be accurately evaluated. Information about environmental conditions such as type of agriculture, water schemes, settlements, and garbage collection systems that contribute to breeding of mosquitoes is not available so we have not been able to identify possible environmental factors associated with disease occurrence.

\section{Conclusion}

Our retrospective cross-sectional study demonstrated a propagated spread of CHIKV fever during the outbreak period from July 2014 to December 2014 in Western Jamaica with the peak at the end of October. Main urban cities, such as Montego Bay and Lucea, were identified as having high number of cases. Clinical symptoms of the disease were also described in our study with the most common symptoms being fever and arthralgia. Although a majority of infants aged $<2$ years had up to four symptoms $(80 \%)$, the percentage of infants with higher numbers of symptoms (9-10) was higher than in older age groups. On the other hand, back pain was found to occur significantly more in older patients. Those with arthritis as a pre-existing condition were more likely to have a headache, asthenia, back pain, and periarticular edema. These findings can help public health officials develop an effective program to prevent the spread of outbreaks by focusing on crowded urban cities. Special groups in the population that are more likely to develop more severe disease such as young infants and people with pre-existing conditions such as arthritis should be more closely monitored to better manage disease outcome.

\section{Acknowledgments}

This research was supported by the Minority Health International Research Training (MHIRT) grant no. T37-MD001448 from the National Institute on Minority Health and Health
Disparities, National Institutes of Health, Bethesda, MD, USA, and the Western Regional Health Authority (WRHA), Montego Bay, Jamaica.

\section{Disclosure}

The authors report no conflicts of interest in this work.

\section{References}

1. World Health Organization. Chikungunya. [Updated May 2015] Available from: http://www.who.int/mediacentre/factsheets/fs327/en/. Accessed March 30, 2016.

2. Pan American Health Organization (PAHO). Preparedness and Response for Chikungunya Virus: Introduction in the Americas. Washington, DC: PAHO; 2011. Available from: http://www.paho.org/hq/ index.php?option $=$ com_docman\&task $=$ doc_download\&gid $=16984 \&$ Itemid=\&lang=en. Accessed March 30, 2016.

3. Smalley C, Erasmus JH, Chesson CB, Beasley DWC. Status of research and development of vaccines for chikungunya. Vaccine. 2016;34(26):2976-2981.

4. Center for Disease Control and Prevention. Help Control Mosquitoes that Spread Dengue, Chikungunya, and Zika Viruses; 2015. Available from: http://www.cdc.gov/zika/pdfs/control_mosquitoes_chikv_denv_ zika.pdf. Accessed March 30, 2016.

5. Caglioti C, Lalle E, Castilletti C, Carletti F, Capobianchi MR, Bordi L. Chikungunya virus infection: an overview. New Microbiol. 2013; 36(3):211-227.

6. Nasci RS. Movement of chikungunya virus into the Western hemisphere Emerg Infect Dis. 2014;20(8):1394-1395.

7. Weaver SC. Arrival of chikungunya virus in the new world: prospects for spread and impact on public health. PLoS Negl Trop Dis. 2014;8(6):e2921.

8. Tsetsarkin KA, Vanlandingham DL, McGee CE, Higgs S. A single mutation in chikungunya virus affects vector specificity and epidemic potential. PLoS Pathogens. 2007;3(12):e201.

9. Rezza G, Nicoletti L, Angelini R, et al. Infection with chikungunya virus in Italy: an outbreak in a temperate region. Lancet. 2007;370(9602): 1840-1846.

10. Mowatt L, Jackson ST. Chikungunya in the Caribbean: an epidemic in the making. Infect Dis Ther. 2014;3(2):63-68.

11. Weaver SC, Osorio JE, Livengood JA, Chen R, Stinchcomb DT. Chikungunya virus and prospects for a vaccine. Expert Rev Vaccines. 2012;11(9):1087-1101.

12. Crossan A. Jamaica Declares a State of Emergency to Try to Stop the Spread of Painful Chikungunya Virus. PRI's the world; 2014. Available from: http://www.pri.org/stories/2014-10-21/jamaica-declares-stateemergency-try-stop-spread-painful-chikungunya-virus. Accessed March 30, 2016.

13. $\mathrm{PAHO} / \mathrm{WHO}$. Information for healthcare providers chikungunya fever. Available from: http://www.paho.org/hq/index.php?option= com_docman\&task=doc_view\&Itemid=270\&gid=23974\&lang=en. Accessed April 4, 2016.

14. Department of International Economic and Social Affair. Provisional Guidelines on Standard International Age Classification. United Nation, New York, NY; 1982. Series M (74):27. Available from: http://unstats.un.org/ unsd/publication/SeriesM/SeriesM_74e.pdf. Accessed March 30, 2016.

15. Center for Disease Control and Prevention. Principles of Epidemiology in Public Health Practice, Third Edition. An Introduction to Applied Epidemiology and Biostatistics [Updated May 2012]. p76. Available from: http://www.cdc.gov/ophss/csels/dsepd/ss1978/lesson1/section11. html. Accessed March 30, 2016

16. Leparc-Goffart I, Nougairede A, Cassadou S, Prat C, de Lamballerie X Chikungunya in the Americas. Lancet. 2014;383(9916):514.

17. Gubler DJ. Resurgent vector-borne diseases as a global health problem. Emerg Infect Dis. 1998;4(3):442-450. 
18. Census of Population and Housing - Jamaica 2011. Available from: http://statinja.gov.jm/Census/Census2011/Census\%202011\%20 data\%20from\%20website.pdf. Accessed November 5, 2016.

19. Center for Disease Control and Prevention. Chikungunya Information for Vector Control Programs. Revised March 9, 2015. Available from: http://www.cdc.gov/chikungunya/pdfs/chikv_vectorcontrol.pdf. Accessed March 30, 2016.

20. Dunn L, Dunn H. Women's Rights, Gender and ICTs: Empowering Household Workers in Jamaica. Global Information Society Watch; 2013:146-150. Available from: https://www.giswatch.org/sites/default/ files/jamaica_gisw13.pdf. Accessed March 30, 2016.

21. Morris C, James K, Laws H, Eldemire-Shearer D. Health status and health-seeking behaviour of Jamaican men fifty-five years and over. West Indian Med J. 2011;60(3):322-329.

22. Feldstein LR, Ellis EM, Rowhani-Rahbar A, Halloran EM, Ellis BR. The first reported outbreak of chikungunya in the U.S. Virgin Islands, 2014-2015. Am J Trop Med Hyg. 2016;95(4):885-889.
23. Kumar NP, Suresh A, Vanamail P, et al. Chikungunya virus outbreak in Kerala, India, 2007: a seroprevalence study. Mem Inst Oswaldo Cruz. 2011;106(8):912-916.

24. Central Intelligence Agency, the World Fact Book; 2015. Available from: https:/www.cia.gov/library/publications/the-world-factbook/ fields/2010.html. Accessed March 30, 2016.

25. Levitt NH, Ramsburg HH, Hasty SE, Repik PM, Cole FE Jr, Lupton HW. Development of an attenuated strain of chikungunya virus for use in vaccine production. Vaccine. 1986;4(3):157-162.

26. Chang LJ, Dowd KA, Mendoza FH, et al; VRC 311 Study Team. Safety and tolerability of chikungunya virus-like particle vaccine in healthy adults: a phase 1 dose-escalation trial. Lancet. 2014;384(9959): 2046-2052.

27. Ramsauer K, Schwameis M, Firbas C, et al. Immunogenicity, safety, and tolerability of a recombinant measles-virus-based chikungunya vaccine: a randomised, double-blind, placebo-controlled, active-comparator, first-in-man trial. Lancet Infect Dis. 2015;15(5):519-527.
Research and Reports in Tropical Medicine

\section{Publish your work in this journal}

Research and Reports in Tropical Medicine is an international, peerreviewed, open access journal publishing original research, case reports, editorials, reviews and commentaries on all areas of tropical medicine, including: Diseases and medicine in tropical regions; Entomology; Epidemiology; Health economics issues; Infectious disease; Laboratory
Dovepress

science and new technology in tropical medicine; Parasitology; Public health medicine/health care policy in tropical regions; and Microbiology. The manuscript management system is completely online and includes a very quick and fair peer-review system. Visit http://www.dovepress. com/testimonials.php to read real quotes from published authors.

Submit your manuscript here: https://www.dovepress.com/research-and-reports-in-tropical-medicine-journal 